\title{
Research on Servant Leadership Models under the Background of Public Hospitals
}

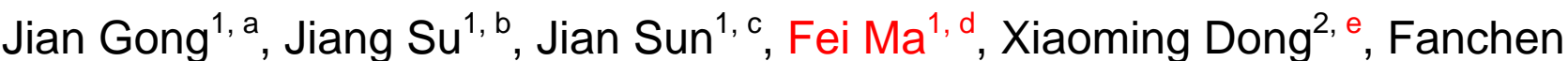 \\ Meng $^{3, \mathrm{f}}$, Mingyu Cong ${ }^{1, \mathrm{~g}}$ (corresponding author) \\ ${ }^{1}$ Qiqihar Medical University, Qiqihar, 161006, China \\ 2 The Second Affiliated Hospital of Qiqihar Medical University, Qiqihar, 161006, China \\ ${ }^{3}$ The Third Affiliated Hospital of Qiqihar Medical University, Qiqihar, 161006, China \\ ${ }^{a}$ email, ${ }^{b}$ email, ${ }^{\mathrm{c}}$ email, ${ }^{\mathrm{d}}$ email, ${ }^{\mathrm{e}}$ email, ${ }^{\mathrm{f}}$ email
}

Keywords: Public hospital, Servant leadership, Leadership effectiveness

\begin{abstract}
Oriented serving the staff, the servant leadership in essence goes beyond the previous organizational interests and innovates a new leading model. In public hospitals, the servant leadership model includes the models to treat employees, performance, and work. This paper discusses the models of servant leadership and the advantages of servant leadership in public hospitals to provide some references for the relative researchers.
\end{abstract}

\section{Introduction}

Different from the traditional leadership style, servant leadership regards service as the core, staff oriented, staff attention, staff development, organizational benefits, and opportunities for employees to participate in leadership. The motivation of servant leadership is not to control other people, but to make followers more active, outgoing, wise, creative and self-controlling. After reading the literature, it is found that the domestic and foreign scholars mainly define the servant leadership from the following angles. The source of leadership rights. The service-oriented leadership emphasizes that the leader is both the owner and the servant of power, and his nature is always of the qualities of being helpful. The purpose of servant leadership is to provide convenience to subordinates. Leadership goals. Servant leadership is a kind of leadership behavior that takes the interests of the leader and the organization as the first, and can sacrifice itself for the collective benefit. Service leaders seek service to others, and they are willing to share power and status with members, individuals, goals and others in order to achieve organizational goals. Leadership process concerns. Servant leadership is the leading activity that focuses on subordinates during the process of exercising power. Managers should lead the organization by caring and fostering subordinates, building trust within the organization, and encouraging cooperation. The trait of leadership itself. Service leader with respect subordinates, subordinates must contribute, motivate subordinates' creativity traits, leadership in organizations is not only the power of the owner, is to have a common goal, good subordinates and employees of learners, good listener, no breach of privilege and sincere communication and motivate others. The director of the Department of public hospitals and hospital leaders should fully understand the servant leadership behavior, and the influence of mode of trust, commitment and sense of service to employees, and strive to create a good working atmosphere, stimulate the work efficiency, so as to promote the overall progress of the public hospital.

\section{Models of Servant Leadership in Public Hospitals}

The Leadership Model to Treat Employees. A public servant leader will listen to employees' opinions, opinions and ideas. They try to understand the will of team members and help them define the team's will. They are good at understanding employees' opinions, really value their employees' ideas and are willing to adopt their views. They are not only good at listening to their employees, but 
also good at listening to their own voices, understanding their own body, attitude and mood to convey information to employees. A public servant leader puts himself in the shoes of his employees and understands the feelings and needs of his employees. People want other people to understand and identify with their unique state of mind. Therefore, servant leaders always try to understand the environment and problems faced by employees from an employee's point of view. They assume that employees have a good motivation. Therefore, even if they do not accept the behavior and performance of certain employees, they will not neglect these employees. Employees will be frustrated by their failure to achieve their aspirations and aspirations. Public servant leaders are very concerned about the mental health and mental status of employees. Employees suffer from all sorts of emotional injuries, and they try their best to cure their traumas and eliminate their feelings of sadness. Many European and American scholars believe that the ability to heal other people's traumas is an effective leadership skill that leaders must master. And being good at curing the trauma of oneself and others is a specialty of the servant leader. Awareness refers to the ability of leaders to obtain information from the environment and to understand their environment. Public servant leaders know very well what is happening around them and form their own opinions and make relevant decisions according to the information they obtain from the environment. They reflect, understand by others on their own views, continuous learning, theory with practice and other methods, increase their knowledge, improve their awareness of themselves and the surrounding environment, in order to observe their surroundings. Their ability to understand the environment also helps them understand ethical and values issues.

The Leadership Model to Treat Performance. Public hospitals should pay attention to the assessment of the behavior and effectiveness of managers' servant leadership, and mainly reward and promote managers according to the results of the examination. For example, in the form of questionnaires, please ask the direct subordinates of managers to evaluate the behavior of servant leadership of managers. And based on employee satisfaction, employee turnover rate, team performance and customer satisfaction indicators, to assess the effect of servant leadership of managers. Conception refers to the ability of leaders to look far ahead. Public servant leaders try their best to improve their imagination. They will look at the vision of the organization through their day-to-day job responsibilities, conceive ways to organize their vision, and encourage employees to conceive of the vision of the organization. The traditional managers only consider the short-term business objectives of enterprises, but often ignore the long-term development prospects of enterprises. Public servant leaders not only focus on day-to-day management, but also conceive of the vision of the enterprise. Foresight refers to the ability of a leader to foresee future situations. A public servant leader has a remarkable ability to anticipate future events. This is not to say that they can always accurately anticipate their decisions affect the organization, but said they would seriously sum up the lessons of the past, a deep understanding of the reality of the current organization, by reflection, predict their decisions may produce results. Many European and American business managers believe that the ability of a public servant leader to foresee future trends is an important ability for them to improve their leadership. It is better for public hospitals to adopt a one-on-one approach. Ask the head of the human resources department to inform the management of the results of each examination. On the one hand, it shows the importance of the public hospitals to the managers, and firmly believes in their servant leadership. On the other hand。 Let managers know employees' evaluations of their servant leadership behavior, affirm their achievements, and work with them to analyze deficiencies so as to help them improve their work.

The Leadership Model to Treat Work. Public servant leaders think they don't own a position, but play the role of stewardship for the benefit of society. Therefore, they attach great importance to the responsibility of organizations to society and try their best to improve the ability of organizations and their members to make greater contributions to society. The servant leader pays great attention to the personal development of employees. They will have an in-depth understanding of the needs of their employees in terms of their mental, professional and personal needs, and will do their best to create opportunities for personal development. They will help employees' career development, pay 
attention to employees' ideas and suggestions, encourage employees to participate in organizational decision-making, and actively help laid-off workers get re employment. A public servant leader has a strong sense of community. They build employee communities within the organization and gradually enhance their community spirit. They consider themselves as stewards of the organization, and employees are their partners. They put the organization and employee interests on their personal interests, to serve the interests of employees, and to encourage all employees to lead other members of the community, for the other members of the community service, enhance mutual communication, community members to mutual understanding, mutual respect, mutual love, mutual support and cooperation, and enhance the cohesion of employees the sense of belonging to the organization. In addition, servant leadership will be through the cultural construction of public hospitals, so that the majority of employees to form the values, beliefs and norms, enhance the team spirit of employees, motivate employees to work together to achieve the vision of the organization. Service leaders are happy, voluntary, and not passive and compulsive in the service of others. Service leaders do not put economic interests or organizational benefits in the first place. Because of their respect for the characteristics of subordinates, the most fundamental purpose is to promote the overall development and progress of hospitals.

\section{Advantages of Servant Leadership in Public Hospitals}

Strengthen Trust Sense. The head of each section of a public hospital should take the initiative to care for employees, and establish a relationship between employees and others who believe in each other. Public servant leaders put themselves in the shoes of their employees and fully trust their employees. In public hospitals, public servant leaders have a keen insight and set an example to their employees. That's the reason why they won the trust of employees. Leaders care for their employees, serve their employees, create a good staff community within the organization, and enhance their trust in their employees. In addition, servant leadership will also influence the trust culture of the enterprise and enhance the mutual trust and trust of the employees through the trust culture. In public hospitals, there is a significant positive correlation between servant leadership behavior and employees' trust of leaders and organizations. Compared with public servant leaders, employees are more trusting of public servant leaders and their leading organizations. In public hospitals, public servants, leaders, candid communication, vision, behavior, and escrow enhance their trust in them. Communication behavior refers to the idea that leaders value employees and actively listen to employees' opinions and opinions. Vision behavior refers to the leader's prediction and planning of the organization's future needs, development tasks and long-term goals, and analyzes the future situation and problems of the organization. Escrow refers only to the leader's commitment to the interests of others and organizations, and to the development of employees and organizations.

Improve Input Degree. Independent director of the Department of public hospitals should respect the staff of the scope of work, to encourage employees to take responsibility, not rigid; provisions for complicated public hospitals, but also in the foundation does not violate the principles, flexible execution. Appropriate empowerment is given to employees to make them work more successfully, so that employees' sense of responsibility will be greatly improved. It is suggested that the head of the Department can understand and pay attention to this difference, and adopt appropriate leadership behavior to motivate employees' work enthusiasm according to the characteristics of the work department. For example, the work of doctors and nurses, administrative staff in nature is different, the doctor is mainly responsible for the diagnosis and treatment of patients, professional, independent and strong, to lead them in addition to emphasize professional, pay more attention to communication skills and humane management. For young doctors, they need to listen to their voices, understand and help them at work. And the nursing staff to direct patient care, and most of the rest of the work shift, life is not normal, the department director should always pay more attention to their health and family life, so that they can really feel the department director can appreciate their hard work. Treat the medical and administrative personnel is the same, so public hospital staff will have very strong centripetal force, work efficiency can be improved. When employees have good opinions 
and suggestions, as long as they are reasonable, they should be accepted with an open mind, even if they are different from their own ideas. In life, if employees are in a bad mood, they can care more about them, understand their practical difficulties, and give them sincere help, which will make employees feel a sense of belonging, thus putting more effort into their work.

Enhance Service Awareness. Service awareness refers to the common view of employees regarding policies, management measures and procedures for organizational requirements, rewards, support services and services. Managers in the organization to create a good service atmosphere, can enhance staff awareness of service orientation, motivate employees to provide customers with quality services. In public hospitals, service leaders communicate service oriented values to employees. They develop service-oriented corporate policies, management strategies and procedures; public servant leaders recognize and reward employees who fully implement enterprise management policies and procedures and achieve corporate vision. The public hospital staff, if can feel the atmosphere of the organization and management department is appropriate. Correlation analysis of the dimensions of job involvement dimensions in leadership behavior, only work oriented dimensions of job responsibility dimensions did not reach significant level, indicating that leadership behavior in the public hospital department director, if only to emphasize the execution of tasks, and not pay attention to staff's opinions and suggestions, and rights issues that will not be able to improve employee job involvement degree, as the competent departments must pay attention to this point. It can be seen that the servant leadership behavior can help to enhance the service atmosphere of the organization. Servant leadership in service oriented enterprise vision, pay attention to employee and customer interests, they encourage employees to participate in decisions, share information, and employees to help staff development, will attach great importance to convey their quality of service, support service information to employees, so that employees can feel the strong atmosphere of the service, and in this the atmosphere in the effort to do service work.

\section{Conclusion}

Servant leadership is a new theoretical angle in the field of public hospitals. We explored the models of servant leadership in public hospitals, and studied the influence of servant leadership. Leaders of public hospitals should pay attention to the shaping and training their own leadership style, give more emotional care and psychological comfort to subordinates, fulfill their social and social responsibilities to promote better development of hospitals.

\section{Acknowledgement}

The paper is one of the results of Soft Science Project of Science\& Technology Bureau in Qiqihar (Foundation Project) named Effect and Mechanism of Servant Leadership on Subordinates' Quality Service in Public Hospitals (Grant No. RKX-201414).

\section{References}

[1] Anderson R J. Building hospital-physician relationships through servant leadership[J]. Frontiers of health services management, 2003, 20(2): 43-47.

[2] Park N K, Lee H, Lee T, et al. Correlations among emotional labor, servant leadership, and communication competence in hospital nurses[J]. Korean Journal of Occupational Health Nursing, 2015, 24(2): 57-66.

[3] Yancer D A. Betrayed trust: healing a broken hospital through servant leadership[J]. Nursing administration quarterly, 2012, 36(1): 63-80.

[4] Chi J L, Chi G C. The impact of servant leadership on job burnout among employees of a Christian hospital[J]. International Journal of Management and Human Resources, 2013, 1(1): 86-110. 